\title{
Intimacies, Relationships and Socialities: South Asians and Racialist America in the Early Twentieth Century
}

\section{Ahmed Afzal}
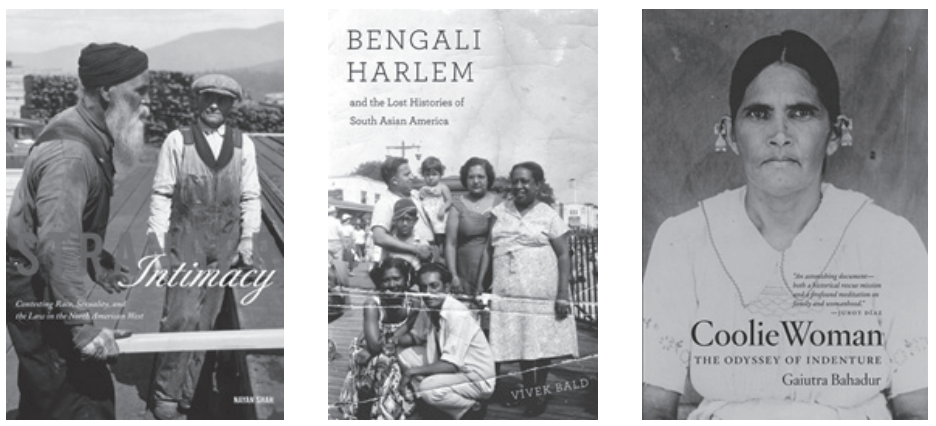

STRANGER INTIMACY: Contesting Race, Sexuality, and the Law in the North American West. By Nayan Shah. Berkeley: University of California Press. 2011. BENGALI HARLEM AND THE LOST HISTORIES OF SOUTH ASIAN AMERICA. By Vivek Bald. Cambridge, MA: Harvard University Press. 2013. COOLIE WOMAN: The Odyssey of Indenture. By Gaiutra Bahadur. Chicago: The University of Chicago Press. 2014.

Much of the scholarly research on South Asian Americans has focused on the post-1965 period. The landmark U.S. Immigration and Naturalization Act of 
1965 abandoned prior legislation that had used race as the basis of immigration to the United States. The 1965 legislation also discarded the national origins quota system that had favored European immigration and severely restricted Asian immigration to the United States until the end of World War II. Following the passage of the 1965 Act, Asia became a major source of immigration to the United States. ${ }^{1}$ Interdisciplinary studies about the South Asian experience have documented diasporic and transnational community formations and illuminated issues such as racism, class, gender roles, sexuality, and religious and national belonging.

Pre-1965 South Asian immigration to North America has received comparatively little attention. Anthropologist and historian Karen Leonard's Making Ethnic Choices: California's Punjabi Mexican Americans (Temple University Press, 1992), historian Joan M. Jensen's Passage from India: Asian Indian Immigrants in North America (Harvard University Press, 1988) and anthropologists Norman Buchignani and Doreen M. Indra's Continuous Journey: A Social History of South Asians in Canada (McClelland and Stewart, 1985) are among the few book-length studies that have documented the South Asian immigrant experience in North America in the early twentieth century. This scholarship has focused on the mostly Punjabi agricultural workers in rural California, the U.S. Southwest, and Canada.

The three books reviewed in this essay build on the above pioneering scholarship and also greatly expand our understanding of the diversity and breadth of pre-1965 South Asian immigrant experiences. Bengali Harlem and the Lost Histories of South Asian America (2013) by comparative media studies scholar Vivek Bald elaborates the experiences of the mostly Bengali Muslim men who were peddlers and merchants in New Orleans and ex-seamen in New York during the early decades of the twentieth century. In Stranger Intimacy: Contesting Race, Sexuality, and the Law in the North American West (2011), historian Nayan Shah explores the everyday life of South Asian farm workers in Canada, California, and the American Southwest. Journalist Gaiutra Bahadur's Coolie Woman: The Odyssey of Indenture (2014) documents the experiences of male and female indentured laborers who traveled to the Caribbean and South America for work on sugar and rubber plantations.

These three exemplary and eminently readable books are essential contributions to the literature on South Asians in the Americas, critical race and gender theory, and early twentieth century American history. The meticulous research yields a multitude of surprises and rewards for the reader. These books provide important insights into the political economy of international population movements in the shadow of severely restrictive, if not prohibitive, racialized immigration policies. ${ }^{2}$ Indeed, the two empires - Great Britain and the United States - provide a critical historical backdrop for understanding the economic circuits that structured South Asian migration. This scholarship shows how race, gender, sexuality, and the law were complexly intertwined in shaping pre-1965 South Asian immigrant experiences. 
In spite of such important interventions, it is the exploration of intimacies, relationships, and socialities that makes these books deeply compelling, thoroughly engaging, and richly textured. In this review, I focus on this troika found in the three books as a lens for illuminating South Asian immigrant experiences in the late nineteenth century and the early decades of the twentieth century. In so doing, the discussion here focuses on the production, transgression, and contestations of attachments, engagements, and community interactions that developed among mobile populations, and were shaped by a range of "verbal and gestural cues, ethnical codes, and cultural frames" (Shah 55). As Nayan Shah notes in Stranger Intimacy, "migratory work and transportation crossroads produced environments of compulsory sociality, but it was the appetite for passionate engagement, the determination to smash alienation, and the desire for visceral solidarity that created both fleeting and enduring relationships" (55). What insights then can be gleaned about identity, kinship relations, gender, and sexuality through a research focus on the social and sexual intimacies, relationships and socialities as discussed in these three books? Moreover, what do the multitude of associations forged by South Asian migrants tell us about race, citizenship, and belonging? And finally, what are the implications of this knowledge for historiographies of early twentieth-century American culture and society?

\section{Peddlers, Seamen and Factory Workers}

In Bengali Harlem, Vivek Bald illuminates the life experiences of South Asian silk peddlers, merchants, sailors, and industrial workers. Working-class Muslim men from villages in East Bengal (now Bangladesh), Kashmir, Punjab, and the Northwest Frontier (now Pakistan) constituted the majority of this population. As sojourning laborers, these men were "among the many populations of peasants and workers whose traditional means of livelihood had been disrupted by colonization, industrialization, and the mechanization of agriculture, and who traveled across oceans to access the jobs and markets available in the United States" (9).

In the late nineteenth and the early twentieth century, there was a growing demand for "Indian" and "Oriental" goods - specifically, finely embroidered silk and cotton fabrics (known as chikan) produced by Bengali women. These goods were coveted as a part of the elite and subsequently middle-class and workingclass consumer cultures in the United States. Bengali peddlers routinely traveled back and forth between the United States and British colonial India, bringing with them fabrics and "Oriental" goods for sale in the United States.

Networks made up of kinfolk were critical to the viability and success of Bengali business operations in the United States. Over time, these networks encompassed several states in the Northeast, Midwest, South, and Southwestern United States. Bengali peddlers relied on these networks to identify business opportunities, acquire local knowledge, and evolve strategies to navigate exclusionary immigration laws. As Bald shows, "the peddlers ... operated as a 
network; they shaped, structured, and coordinated their activities to ensure that people, information, money, and goods continued to flow across borders, even as conditions on the ground changed" (41).

These networks extended to domestic life and to living arrangements. Peddlers and the subsequent waves of ex-seamen who jumped ship at port cities created single-sex households, living with other migrant men in dormitories, boardinghouses, and apartments in cities such as New York City and New Orleans. These domestic arrangements provided the infrastructure necessary to carry out business and to expand businesses in other cities. These spaces also created opportunities for mentorship and companionship. Bald provides insights into the everyday life in private domestic spaces that emerged in Tremé in New Orleans: "Although [Bengali peddlers] spread out across the city to sell their goods each day, here in these houses they shared the domestic and intimate aspects of their lives, cooking and eating together, washing and cleaning, likely sharing beds, caring for those who fell ill, helping each other navigate the challenges of their daily lives, and spending leisure time with each other" (72).

The presence of South Asian migrants in localities like Tremé expands our understanding of the multiethnic and multiracial composition and the heterogeneity of community formations in such spaces that included African Americans from the South, as well as working-class Irish, Italian, German, Syrian, and Chinese. In the late nineteenth century, Tremé emerged as a nucleus for New Orleans's free persons of color communities. In the 1880s and the 1890s, Anglo Americans solidified their control of Louisiana's legislature through measures such as the Separate Car Act that prohibited "colored" communities from "riding on [streetcars] or in sections designated for whites. Although members of New Orleans' free person of color community challenged the Separate Car Act, the U.S. Supreme Court, in its Plessy v. Ferguson decision, upheld the law's constitutionality. This cleared the way for Louisiana to enact a series of other segregation laws as well as a new state constitution that effectively disfranchised the state's citizens of African descent" (56).

The incorporation of Bengali peddlers in New Orleans' racialized geographies and racial orders was complicated by their classification variously as "Black," "White," "Mulatto," "Oriental," or "Hindoo." Yet, as Bald explains, "the dark hue of their skin ultimately determined where they would return at the end of each day, the type and quality of the houses in which they would live, the health conditions they would face, the public facilities they could and could not access, and the risks that attended their daily movements" (52). Outside of spaces like Tremé, Bengali peddlers — objectified and racialized as exotics — creatively appropriated their "foreignness" to navigate racially segregated cities and localities for business. These men learned to perform an expected Indian authenticity through dress, commerce, and behavior. These men "built their operations within the constraints of Jim Crow, shuttling back and forth between an Indianness they performed for their customers and a blackness they shared with New Orleans' and other cities' populations of African descent" (52). 
Although this transient population was almost exclusively male, women were central to the viability and success of the business operations. Bengali women who had stayed behind in their ancestral villages produced the embroidered goods that were sold in the United States. These women also sustained familial networks as they "tended to the homes, land, and families that the peddlers left behind for months or years at a time" (8). Equally, the women of color-African American, Creole of Color, and Puerto Rican - that these men married anchored their lives in the United States. As Bald emphasizes, these women were critical to the viability of the business operations in the United States: they "had local knowledge, local networks, and a local cultural fluency far beyond those of their immigrant husbands" (74-75). Further, given the tenuous legal status of the Bengali peddlers, it is instructive that it was usually African American and Creole of Color women who provided room and board to this vulnerable population, demonstrating the varied roles that they played in the lives of Bengali peddlers.

By the 1930s, the mechanization of goods and stringent immigration laws led to the decline of peddler networks. Some of these men began to sell clothes and other goods for working-class populations in the communities in which they resided. Many of them married local women, "put down roots in the city, and established supply lines of cloth goods from their associates and kin in India" (74), thus becoming incorporated into black New Orleans.

In the first decade of the twentieth century, Indian maritime workers also began arriving in the United States, increasing in numbers in the years following the end of the First World War. According to Bald, "beginning around the time of the First World War, hundreds of Indian maritime workers, men who labored in the engine rooms and kitchens of British steamships, escaped into the crowded waterfronts of New York, Philadelphia, and Baltimore in search of less brutal and captive work and better wages onshore" (7). Explaining the trajectory of their journey further, Bald states, "After signing onto ships in Calcutta and Bombay, they worked under indenture-like conditions at the mercy of British ships' masters for months and years at a stretch. During the war, however, these men found that their labor was in demand in U.S. steel, shipbuilding, and munition industries, and they formed clandestine networks to help one another jump ship and make their way inland to factory towns" (7).

The "expansion of the British Empire, the opening of the Suez Canal, the arrival of steam power, and the growth and acceleration of world travel and trade" (97) had facilitated the migration of Bengali peddlers. The migration of Indian seamen, made up mostly of men from farming families, arose due to the expansion of maritime trade, the unionization of European seamen, and the need for a less regulated industrial workforce on British merchant vessels. Explaining the racialization of the workforce, Bald states, "British shipping companies justified their exploitation of Indian workers with a racial mythology that portrayed men from the colonies as inferior to Europeans...Indian men were also more 'suited' to the heat of the boiler room or to servile and domestic tasks above decks" (105). 
Much like the New Orleans Bengali peddlers, the ex-seamen who jumped ship also built networks to provide information to each other, and to find work in the industrial belt of the U.S. Midwest. According to Bald, "these men clearly relied on one another; as Indian seamen deserted and found work in the United States, they fueled a chain migration in which they helped others from their families, villages, regions, and former ships desert and find work as well" (123). Significantly, these networks transcended ethnicity and race. Indeed, "Indian seamen drew on the knowledge, assistance, and labor of many other people, from the American women of color a number of them married to waterfront shopkeepers, anti-colonial exiles, and other sailors-Arab, Irish, and British. The spaces they inhabited and moved through were comprised of and animated by all these other people" (123).

Much like the Bengali peddlers in cities like New Orleans, ex-seamen also became incorporated into multiethnic and multiracial communities. Bengali-Puerto Rican-African American community formations in Harlem in the 1940s and the 1950s are an important case in point. According to Bald, "if [ex-seamen] began their lives uptown as a small group of outsiders amid the much larger historymaking migrations in Harlem, by midcentury they were deeply ingrained in the physical and social landscape of the neighborhood, in its cultural and institutional life, and in the cultural and institutional life of the city as a whole" (188).

Yet, in spite of such incorporation into multiethnic and multiracial communities, these multiracial families are rendered invisible and lost because - much like Bengali peddlers and merchants in Tremé- they and their descendants became absorbed in the history of black America. These relationships and community formations are also rendered invisible in historiographies of South Asian Americans that have focused on cases such as U.S. v. Bhagat Singh Thind (1923), which were premised on assertions of whiteness and a strategic distancing from communities of color. Such denouncements are complicated by the lived experiences of Bengali peddlers, merchants and ex-seamen that show how South Asian men not only worked and lived alongside communities of color, but also developed intimate relationships and ties within these communities. The lives and experiences of South Asian farm workers in British Columbia, California, and the American southwest - the subject of Stranger Intimacy — show similar variegated investments in multiethnic and multiracial sociality, relationships, and communities.

\section{South Asian Farm Workers, Laborers, Businessmen and Farm Owners}

In Stranger Intimacy, Nayan Shah explores South Asian immigrants' everyday lives - specifically, as laborers, labor contractors, farm tenants, businessmen, and farm owners - by examining law as "a form of knowledge and reasoning, and strategy of governance" (9), and legal disputes that implicated citizenship, nationhood, gender, sexuality, class, and race. The book covers a multitude of 
fascinating cases that provide insight into the construction of intimacies between South Asian male transient migrants and white, African American, and Latino men and women. Shah taps into the archives, notably legal records, to illuminate the "web of local social and economic relations" (9) within which these migrants were embedded. What unfolds is a remarkable and fascinating narrative about a population that is rendered invisible in dominant historiographies of the "American immigrant experience" that privilege conventional community formations and settlement patterns. Dominant historiographies elide the "elastic and shifting movement, impermanence, and the discontinuous array of work, affiliations, places, friends, and strangers" that characterized the life of South Asians involved in the North American agricultural economy (6).

Equally, the volume erodes dominant mythologies of the nuclear family as a "model for social vitality and political participation" (6) and instead reveals the varied forms of families and households that are typically labeled as "pathological, aberrant, and incompatible with cultural support and political privilege" (6). These included transnational families that were spread over multiple nationstates and interracial marriages in the United States. Households also included a wide range of temporary domestic arrangements, notably, all-male households in settings such as dormitories, boardinghouses, and bunkhouses. Often, these all-male living spaces were multiethnic and multiracial in composition and included transient migrants from several different countries. In Shah's astute analysis, these all-male households were also spaces for the productions of sexual intimacies and homosocialities.

In elaborating the intimacies that developed between "strangers," Shah destabilizes western epistemologies of sexual orientation and identity that presume a fixed sexuality (for example, as either homosexual or heterosexual). Instead, cases of queer intimacies documented in the book reveal a range of transgressive sexual relationships and experiences that were shaped by specificities of context, and the "considerable variance of erotics, relations, and meanings in society" (8). As Shah argues, "by challenging the assumption that people are endowed with singular and fixed sexual essences, I am able to analyze the impact of practices, expressions, and interests that are not static and fixed at any life stage but mobile over the life course and social space" (8).

In the late 1800s, these South Asian migrants became the object of racism and nativist violence in part due to the perception that these men were taking jobs away from native-born Americans. Racism was also bolstered by racialized popular representations that constructed South Asian men as immoral and outside of the emerging American heteronormative family, gender, and sexuality. As Shah notes, "Alongside accusations of unfair labor competition with white workers, politicians and newspapers circulated stories about women and children who had been indecently harassed. The claim of defending honor dovetailed with broader assertions that the presence of South Asian men demoralized white working families" (20). 
Shah refers to the murder of a Sikh laborer, Darrah Singh, by an English laborer, Edward Bowen, in Vancouver to illustrate how claims of defending male honor were used to justify violence towards South Asian migrants. Bowen had been fired from his job as a night watchman at a general hospital, had purchased a gun earlier in the day, and then met the turbaned Darrah Singh and Singh's Indian companion at a saloon. Saloons, hotels, and boardinghouses provided a space for transient men to socialize. As Shah suggests, "this homosocial environment satisfied social needs, but physical closeness and signs of sexual desire provoked vigilant anxiety. Attempts to thwart physical intimacy disrupted male camaraderie and redirected its expression as a potential threat to male honor. Racial difference amplified the threat" (33). After an evening drinking together and sharing stories about their lives, Singh invited Bowen to his room at a boardinghouse. Once there, according to Bowen, Singh started to unwind his turban, and take off his trousers and vest, and began to put his hands on Bowen's "privates." Allegedly horrified at the sexual advances, Bowen shot Singh killing him on the spot.

Accounts of what had actually transpired varied. Testimonies from the innkeeper emphasized Singh's honorable character. Witnesses present at the scene noted that Singh was in fact fully clothed at the time of his murder. A friend of Singh testified that Singh was carrying cash in anticipation of his migration to the United States. However, the cash was never found, raising questions regarding the unemployed Bowen's motivations. Bowen's defense attorneys argued that Bowen had acted to defend his honor that was under threat and vulnerable to the immorality of foreign men. The jury disagreed, and returned with a verdict of manslaughter resulting in Bowen's conviction. In spite of the conviction, the case positioned white men as victims "and crystallized how adult men could experience feminized vulnerability. Although the jury refused to condone murder, even in defense of a man's honor, the public culture recognized the dangerous moral and sexual affront, underscoring suspicions of interracial socializing" (35).

Shah also analyzes "legal records of vagrancy, public indecency, and sodomy to illustrate how insistently migrant laborers crafted alternative publics and communicated codes of male honor, privileges, and hierarchy as they strategically remapped spaces and sensibilities labeled as deviant" (10). As Shah argues, "male migrants sought out and created appealing alternatives to and escapes from conventional and traditional domesticity and sociality. These experiments in social relations and intimacies were forged by the challenges of migratory work and life. Through feeling and loving otherwise, migrant males' experimental intimacies were attempts to buffer the material challenges of survival and kept isolation, poverty, and death at bay" (55).

Intimacies between strangers found outlets in clandestine sexual encounters in public spaces such as street corners and alleys. These encounters were the subject of intense state scrutiny, with the police, immigration officials, and even bystanders policing these encounters. For example, local policemen dressed in plainclothes developed creative means such as posing as a potential sexual interest for an unsuspecting South Asian migrant, drawing him into a compromising 
position, entrapping him, and then arresting him on charges of immorality and public indecency.

At times, the encounters that the police were trying to thwart were more than just about satisfying sexual needs and urges. In one case, a drunken Jawalla Singh told a plainclothes police officer that he loved the young sixteen-year-old boy he had been following. In Shah's analysis, "the declarations of friendship, care, and affect by transient and illiterate migrants, who left little other record of their desires and emotions, reveal an emotionally complex world" (71). In making meaning of the complexity of such encounters and relationships, Shah draws attention to transnational idioms of homosociality; most notably the glorification and cultural acceptability of boy-love in certain South Asian literary traditions and cultural contexts that might explain Singh's intentions.

Relationships of dependency in the agrarian economy, such as those between migrant workers, tenant farmers, labor contractors, and landowners are typically examined through the lens of economic relationships and interactions. Shah's analysis extends the potential of such relationships to the domain of sexual intimacies between men and women, and between men. Significantly, Shah shows how social regulations, policing, and the persecution of sexual relations between migrant men and women, as well as between men, normalized middle-class marriage and courtship. These norms were further enforced through legislation such as the Alien Land Laws in the 1910s and the 1920s, which curtailed land ownership by non-citizens. Equally, the consolidation of bureaucratic procedures - such as the registration of economic activities, and the official record keeping of labor contracts, marriage contracts, and civil and criminal proceedings-illustrates state intervention in marking certain social alliances and relations as legal, legitimate, and normative, and others as illegal, deviant, and perverse.

Legal reasoning around sodomy cases and marriage regulations also demonstrate the state's construction of gender, sexual and national norms. In Shah's masterful analysis, these laws and regulations codified erotic, affective, and social relationships as either natural or deviant. As a result, "the wholesale criminalization of sodomy and homosexuality, regardless of consent" (12) shaped conceptions of normative masculinity, and "in the process standardized human subjectivity and generated a socially sanctioned definition of proper relationships" (12).

Gender, sexuality, race, and the law were also intertwined in policing and regulating South Asian mobile populations that were destined for shores in South America. Attention to these experiences is significant in illuminating the experiences of South Asian migrant women during the late nineteenth and the early twentieth centuries.

\section{Indentured Laborers in Guyana}

The late nineteenth century was marked by a number of different international population movements from British colonial India. The British abolition 
of slavery in 1833 created a demand for cheap labor on primarily sugar and rubber plantations in Fiji, Guyana, Jamaica, Mauritius, Trinidad, South Africa, and Suriname. The British sought to meet this demand by recruiting Indian agricultural workers from present-day states of Bihar, Uttar Pradesh, Punjab, Gujrat, and Bengal. From 1838 to 1917, a million Indians traveled from colonial India to British colonies as indentured laborers on plantations across the globe.

In Coolie Woman: Odyssey of Indenture, Indo-Caribbean American journalist Gaiutra Bahadur explores the experiences of Indian indentured laborers, pejoratively labeled as "coolies," motivated by a deeply personal quest to learn more about Sujaria, her great grandmother. Sujaria, a high-caste Brahmin Hindu woman, had arrived in Guyana (then British Guiana) in 1903 as an indentured woman. Coolie comes from "the Tamil word kuli, meaning wages of hire" (xx). As Bahadur explains, "imperial bureaucrats imposed the coolie label on a wide group of native people, from many castes and occupational backgrounds. Most indentured laborers would not have used the word to describe themselves. They registered their protest in folk songs sung for generations ... They felt mislabeled and degraded, unable even to name themselves" (xx). In using this term, Bahadur attempts to reclaim this word, "invest[ing] it with pride and subvert[ing] the old stigma" (xxi).

Coolie Woman documents the journeys of Indian indentured women-journeys that were psychological, physical, personal, and often deeply traumatic. Bahadur's narrative unfolds across several continents: the Indian subcontinent, South America, and North America. It is an intimate portrayal of the story her great grandmother. It is also an epic tale about the countless female Indian indentured laborers and their lives in India, their experiences during the long and arduous voyage to South America, their often traumatic lives on the plantations, and their unrelenting quests to find dignity and meaning as they built lives in Guyana.

Broader social and economic factors provide insights in the migration of indentured laborers. Many of the indentured laborers were previously part of the agrarian labor force, including weavers, who had been displaced due to economic changes under British colonial rule. As Bahadur notes: "The practice of imperial capitalism destroyed traditional livelihoods, plunging weavers into unemployment by flooding India with factory-made textiles from England" (25). High tariffs limited the export of Indian textiles and exacerbated economic vulnerabilities. Additionally, periods of famine displaced large rural populations who traveled to metropolises like Calcutta in search of work and to seek out opportunities to travel abroad for work. Even though migration was commonly perceived as a male enterprise, a considerable number of women were recruited and traveled for work in the British colonies. In fact, ships could not sail unless there were forty women for every one hundred men among the coolies.

A close reading of the situations of women from different backgrounds sheds light on the many different reasons for their migration. For some of these women, the opportunity to work abroad might have provided an escape from oppressive familial and societal conditions such as the prohibition against re-marriage of 
upper caste Brahmin women that left many widows destitute. Young women who were determined not to marry or follow tradition might also have been persuaded by recruiters to travel abroad. For Dalit and the lower-caste Hindu women and sex workers, indenture might have provided opportunities to build new lives in a place where they were not marked by their caste or profession. Perhaps it was the most desperate women, those forsaken by their husband or families for any number of reasons, who made the voyage.

Given the relative absence of firsthand accounts, one can only conjecture as to the reasons that motivated these women to undertake these journeys. As Bahadur states, "missing, with few exceptions, are the voices of the women themselves. They did not leave behind diaries or letters. The vast majority wasn't literate, in English or in any Indian language. They did not tell their own stories, except indirectly, through the often-biased prism of government investigators and court officials who occasionally took their testimonies" (32).

Bahadur poses several questions that allude to more complex rationales: "The relative silence of coolie women in the sum total of history reflects their lack of power. But could it also reflect a strategy by women who had secrets to keep? Is it possible that, on some level, each individual silence was a plan? Could they have harbored ambivalence in their hearts, an ambivalence to account for their actions? ... Is it possible that my great grandmother would not want me to know why and how she left? Would she deliberately disappear behind a curtain to escape questions about her past?" (32) Ultimately, as Bahadur suggests: "Sometimes, I think the women who left India as coolies kept quiet on purpose. It may be that the circumstances were too traumatic to remember, much less proclaim. It may be that their emotions were too conflicted to convey. Perhaps language limited them; they may have lacked the words in English to express the deep dividedness of departure to their children and grandchildren" (48).

Coolie Woman is rich with insights about the voyage itself and life on the sugar plantations in Guyana. The life situations described in the volume converge on the issue of the consensual as well as coercive intimacies that developed between the men and women on the voyage and subsequently in Guyana. However, in Bahadur's analysis, these relationships were often oppressive and abusive. British crew members were equally complicit in the abuse of these women, who often used sex as barter for more and better food and security during the voyage. Bahadur notes that there was an "absence of penalties in the rules against sex with female emigrants - or, for that matter, in the rules against any form of abuse of any indentured emigrants. Some offenders faced consequences; others did not ... Some of those entrusted with protecting emigrants — whose very reason for being was to embody the state's new posture as caretaker, rather than enslaver - were themselves offenders" (57).

Referring to specific cases of violence, abuse, exploitation, and rape of women on the ships, Bahadur emphasizes: "It is hard, in these glimpses, to escape the angle of sexual exploitation by figures of all ranks and races. In these archives of misconduct, the women appear resisting advances. Or, giving in to 
them. Or - in the eyes of many ship officials — courting them. But the records also provide other views of the women: on deathbeds, giving birth, losing children, going mad, being driven to suicide, engaged in infanticide, rejecting or being rejected by shipboard husbands, demanding their husbands prove themselves, stowing away, crying, cursing, possibly in love and clearly in anguish" (61).

The abuse, exploitation, and oppression of indentured women persisted in Guyana. Men greatly outnumbered women on the plantations, and they aggressively courted women as sexual partners. Court records and reports in the local press point to a number of cases of the physical abuse and murders of these women by their husbands, other men on the plantations, and by multiracial and European men. Persecution of these crimes varied greatly - especially in cases that involved an Indian woman and a European male perpetrator. In situations involving European men, most cases fixated on the issue of inadequacy of evidence that ultimately absolved the accused of any wrongdoing. Racial hierarchies privileged and protected European men and criminalized Indian men through racist stereotypes. According to Bahadur, "European observers fixated on what they saw as 'national' character. Although some located the problem in the plantations themselves, mostly they ascribed the murders to possessiveness and promiscuity, traits they saw as inherently Indian ... Indeed, stakeholders in indenture put the blame everywhere but on the system itself. They largely ignored evidence that the killings were tied to indenture - to the institution, rather than the race or the religion" (115-116).

Bahadur is careful not to present these women as only victims, offering examples of everyday forms of resistance such as a woman's refusal to marry men out of pressure. Other examples show how these women engaged in sexual relationships with European administrators as a strategy to acquire financial capital and security. Yet other examples show how women took recourse to the law by lodging complaints of sexual abuse. As evidenced from the folk songs and oral traditions that these women brought with them from India, many women invoked and appropriated the narrative of Ram and Sita in the Hindu mythological text, Ramayana, to make meaning of their trials and oppression. Such acts show their resilience and courage in the face of enormous injustice and adversity, and reveal the complex interplay between resistance and accommodation.

Following the official end of indenture in British colonies in 1919, some of the Indian indentured laborers returned to India. However, most stayed in Guyana. By the late twentieth century, some, like Bahadur's family, had continued their journey as immigrants to Australia, Europe, and North America. However, the legacy of the violent intimacies that had characterized the coolie experience for women persists in contemporary Guyanese society. In the final chapter, Bahadur returned to Guyana and found alarming rates of domestic abuse and violence, in part a legacy of the normalization of violence toward women on the plantations. 


\section{Conclusion}

The three extraordinary and meticulously researched books reviewed here bring to the foreground the lives and experiences of the obscure, the invisible, the abject, and the marginal that often remain concealed within the archives and outside of popular memory or consciousness. The socialities, intimacies, and relationships that become visible in the stories, experiences, and narratives of South Asian immigrants during the pre-1965 period illuminate multiethnic and multiracial community formations. As such, they beg a reconsideration of historiographies not only of South Asian communities in the U.S., but also of Puerto Ricans, Afro-Caribbeans, and African Americans. Finally, these stories also provide a necessary historical lens for making meaning of racism toward South Asian Americans during the contemporary period, as well as an appreciation of multiethnic and multiracial solidarities in the face of persistent oppression, marginality and abjection of communities of color.

\section{Notes}

1. Paul Ong, and John M. Liu, "U.S. Immigration Policies and Asian Migration,” in Contemporary Asian America: A Multidisciplinary Reader, eds. Min Zhou and James Gatewood, (New York: New York University Press, 2000), 449-458.

2. Junaid Rana. Terrifying Muslims: Race and Labor in the South Asian Diaspora. (Durham, NC: Duke University Press, 2011). 